\title{
Kesiapan Psikologis Guru Tk Di Bali Menerima Anak Berkebutuhan Khusus Di Kelas
}

\section{Putu Rahayu Ufianti ${ }^{*}$}

1Universitas Pendidikan Ganesha, Singaraja, Indonesia

*e-mail: puturahayuujianti@undiksha.ac.id

\begin{abstract}
Abstrak
Kurang maksimalnya proses pembelajaran disebabkan karena guru belum memahami karakteristik anak berkebutuhan khusus serta belum memahami program inklusi dan mendesain pembelajaran yang baik. Tujuan penelitian adalah untuk menganalisis kesiapan guru menerima anak usia dini berkebutuhan khusus di kelasnya, dan faktorfaktor psikologis yang mempengaruhi kesiapan tersebut. Jenis penelitian ini adalah kualitatif. Penelitian ini menggunakan metode kuantitatif dan kualitatif dengan sampel 94 orang guru TK dari 23 sekolah, 8 orang diantaranya secara sukarela berpartisipasi dalam diskusi kelompok terarah untuk mendapatkan pemahaman yang lebih mendalam. Instrumen yang digunakan untuk mengumpulkan data adalah kuesioer. Teknik yang digunakan untuk menganalisis data dalam penelitian ini adalah statistik deskriptif dan teknik analisis tematik. Hasil penelitian ini adalah para guru belum memiliki pengetahuan dan keterampilan yang memadai untuk mendeteksi, melakukan asesmen dan menciptakan lingkungan belajar yang memadai dan sesuai untuk anak usia dini berkebutuhan khusus, namun guru memiliki sikap positif dan bersedia menerima anak berkebutuhan belajar di kelasnya. Implikasi penelitian ini yaitu guru hendaknya selalu memperhatikan kesiapan psikologi siswa karena akan mempengaruhi keberhasilan pembelajaran.
\end{abstract}

Kata kunci: kesiapan guru, anak usia dini, berkebutuhan khusus

\begin{abstract}
The learning process is not optimal because the teacher does not understand the characteristics of children with special needs and does not understand inclusion programs and design good learning. This study aims to analyze the readiness of teachers to accept early childhood with special needs in their class, and the psychological factors that influence this readiness. This type of research is qualitative. This study used quantitative and qualitative methods with a sample of 94 kindergarten teachers from 23 schools, 8 of whom volunteered to participate in focus group discussions to gain deeper understanding. The instrument used to collect data was a questionnaire. The techniques used to analyze the data in this study were descriptive statistics and thematic analysis techniques. The results of this study are that the teachers do not have sufficient knowledge and skills to detect, assess and create a learning environment that is adequate and suitable for early childhood children with special needs, but teachers have a positive attitude and are willing to accept children with learning needs in their class. The implication of this research is that teachers should always pay attention to the psychological readiness of students because it will affect the success of learning.
\end{abstract}

Keywords: teacher readiness, early childhood, with special needs

\section{Pendahuluan}

Prinsip penyelenggaraan pendidikan adalah pendidikan diselenggarakan secara demokratis dan berkeadilan serta tidak diskriminatif dengan menjunjung tinggi hak asasi manusia, nilai keagamaan, nilai kultural, dan kemajemukan bangsa (Nufus, Wulandary, \&

\footnotetext{
${ }^{*}$ Corresponding author.

Received 30 Januari 2021; Accepted 1 Maret 2021; Available online 8 April 2021 (C) 2021 MI All Rights Reserved
} 
Wahyuda, 2020; Sinoho, 2011). Meski undang-undang telah secara tegas mengatur pemerataan hak dan kewajiban bagi setiap warga negara untuk mengakses pendidikan, namun masih saja ada anak-anak yang belum mendapatkan akses pendidikan, salah satunya adalah anak berkebutuhan khusus. Anak berkebutuhan khusus adalah anak-anak yang mengalami hambatan dan permasalahan dalam perkembangannya, bisa di satu atau beberapa aspek perkembangan sekaligus (Amka, 2019; Praptiningrum, 2010). Ada yang laju perkembangannya amat lambat, sebaliknya ada juga amat cepat. Semakin dini terdeksi kebutuhan khusus anak, semakin cepat anak mendapatkan penanganan yang sesuai. Anak berkebutuhan khusus memiliki kesempatan dan peluang yang sama dengan anak normal untuk mendapatkan pelayanan pendidikan di sekolah (Cahyani, 2019; Diahwati, Hariyono, \& Hanurawan, 2016).

Permasalahan yang terjadi saat ini di Bali, khususnya di Kabupaten Buleleng adalah masih amat terbatas jumlah sekolah di berbagai jenjang yang melaksanakan pendidikan inklusi, sehingga anak-anak berkebutuhan khusus belum tertangani dengan semestinya. Penelitian yang dilakukan oleh Dewi, Pujianti, \& Magta (2020) juga menyatakan bahwa pendidikan inklusif pada jenjang TK masih jarang ditemukan khususnya di Kota Singaraja. Penelitian yang dilakukan oleh Suastariyani \& Tirtayani (2019) menyatakan bahwa faktor dapat menyebabkan rendahnya jumlah anak berkebutuhan khusus yang memperoleh pendidikan yaitu infrastruktur yang tidak memadai, kurang tenaga pengajar khusus, serta pemahaman masyarakat yang kurang mengenai anak berkebutuhan khusus. Masyarakat masih menganggap satu-satunya tempat belajar bagi anak berkebutuhan khusus adalah di Sekolah Luar Biasa. Masalahnya, persebaran SLB di Kabupaten Buleleng terbatas, hanya ada di kota Singaraja. Dari berbagai tingkat sekolah luar biasa yang ada, tidak ada jenjang TKLB (Taman Kanak-Kanak Luar Biasa), padahal usia dini adalah masa dimana anak-anak bertumbuh dan berkembang paling pesat dibandingkan tahap perkembangan lainnya. Pada masa ini, aspek perkembangan, baik kognitif, emosi, sosial, bahasa dan fisik perlu distimulasi secara optimal (Astuti, 2017; Praptiningrum, 2010). Hasil survey yang dilakukan terhadap dua puluh orang guru TK di Kabupaten Buleleng menunjukkan bahwa setengah dari responden belum memiliki kemampuan untuk mengenali jika salah satu siswa di kelasnya berkebutuhan khusus. Tiga belas responden menyatakan tidak memahami karakteristik anak berkebutuhan khusus, dan seluruh responden menyatakan belum memahami tentang program inklusi dan bagaimana mendesain program pembelajaran untuk anak berkebutuhan khusus di kelasnya. Sementara sembilan belas dari dua puluh responden menyatakan membutuhkan pengetahuan dan ketrampilan untuk melakukan asesmen dan mendesain pembelajaran untuk anak berkebutuhan khusus.

Dalam kasus ini kehadiran lembaga PAUD inklusi menjadi sangat urgen dan krusial, khususnya di Kabupaten Buleleng. Tidak terdapatnya TKLB menjadikan lembaga PAUD atau TK umum menjadi satu-satunya tempat tujuan bagi anak berkebutuhan khusus untuk bersosialisasi dan mendapatkan stimulasi, meskipun biasanya sesuatu yang baru akan dirasakan asing dan tidak mudah diterima. Guru merupakan tokoh penting dalam inklusi di sekolah, oleh karena itu dibutuhkan tenaga guru yang profesional dan memiliki kompetensi dalam menangani anak berkebutuhan khusus (Cahyani, 2019; Widyastono, 2007; Yusuf, 2012). Berdasarkan permasalahan tersebut, perlu dilakukan penelitian lebih lanjut tentang kesiapan guru di TK reguler untuk menerima anak usia dini berkebutuhan khusus di kelasnya. Salah satu faktor penentu kesiapan tersebut adalah sikap guru terhadap anak berkebutuhan khusus dan pendidikan inklusi. Sikap guru terhadap anak berkebutuhan khusus adalah gambaran yang positif atau negatif terhadap komitmen guru dalam mengembangkan anak berkebutuhan khusus yang menjadi tanggung jawabnya, dan juga menggambarkan sejauh mana anak berkebutuhan khusus mendapatkan penerimaan di sebuah sekolah (Habibi, 2017; Hamidaturrohmah \& Mulyani, 2020).

Guru harus memiliki kompetensi sebagai agen pembelajaran yang meliputi kompetensi pedagogik, kepribadian, profesional, dan kompetensi sosial (Kartowagiran, 2015; Umi, Nopriansyah, \& Purnama, 2019). Melalui kompetensi ini guru menjadi professional dalam menjalankan tugasnya yang meliputi mengajar, mendidik, mengarahkan, 
membimbing, melatih, menilai, serta mengevaluasi siswa. Dalam proses pembelajaran guru dituntut untuk dapat memfasilitasi siswa dalam belajar. Saat ini guru dituntut untuk memiliki kompetensi khusus untuk menangani proses pembelajaran pada siswa yang berkebutuhan khusus. Paradigma Guru yang pada awalnya sebagai pengajar (teacher), kini beralih menjadi pelatih (coach), pembimbing (counselor) serta (learning manager) (Khayati, Muna, Oktaviani, Hidayatullah, \& Fauzan, 2020; Lattu, 2012). Guru wajib memberikan dukungan kepada siswa yang berkebutuhan khusus dan memberikan layanan penuh bagi siswa. Sekolah juga wajib memberikan dukungan kepada guru dalam bentuk memberikan kesempatan kepada guru untuk latihan agar dapat digunakan untuk menangani anak berkebutuhan khusus. Selain itu guru juga wajib memberikan contoh melalui sikap positif agar siswa dapat mengikuti pembelajaran dengan senang (Oktiani, 2017; Surahman \& Mukminan, 2017).

Taylor \& Ringlaben (2012) mendefinisikan sikap positif sebagai kecenderungan tindakan yang berupa mendekati, menyenangi, dan mengharapkan objek tertentu, sedangkan sikap negatif adalah kecenderungan untuk menjauhi dan menolak objek tersebut. Melalui sikap positif dari guru, anak berkebutuhan khusus akan mendapat lebih banyak kesempatan dalam bidang pendidikan untuk belajar bersama teman sebayanya, dan akan lebih mendapatkan keuntungan pendidikan semaksimal mungkin (Olson, 2003; Praptiningrum, 2010). Sikap guru yang negatif menggambarkan harapan yang rendah terhadap anak berkebutuhan khusus di kelas inklusi (Cahyani, 2019; Elliot, 2008). Akibatnya kesempatan yang diperolehnya juga lebih terbatas. Taylor \& Ringlaben (2012) menjelaskan pentingnya sikap guru terhadap inklusi, yaitu guru dengan sikap yang lebih positif memiliki pendekatan yang lebih positif untuk inklusi. Guru akan lebih mampu mengatur instruksi dan kurikulum, menyesuaikan materi ajar dengan kondisi siswa bekebutuhan khusus.

Penelitian yang dilakukan oleh Setianingsih (2018) menyatakan bahwa guru yang profesional haruslah selalu bersikap positif dan penuh tanggung jawab dalam mendidik peserta didik terutama untuk menangani anak berkebutuhan khusus. Leatherman \& Niemeyer (2005) menyatakan bahwa sikap guru melalui tiga komponen sikap, yaitu kognisi, afeksi, dan perilaku. Ketiga komponen tersebut tertuang dalam lima bentuk sikap guru terhadap inklusi, yaitu sikap terhadap anak berkebutuhan khusus di dalam kelas, pengalaman mengajar di kelas inklusi, kemampuan guru memperhatikan kebutuhan masingmasing siswa di dalam kelas, kemampuan guru menekankan pentingnya keterlibatan keluarga dari para siswa untuk menyusun program belajar, dan ketersediaan fasilitas dalam kelas, menjadi penunjang kelas inklusi yang efektif. Kesiapan guru dalam menangani anak berkebutuhan khusus dipengaruhi oleh perpaduan tiga faktor, yaitu tingkat kematangan, pengalaman-pengalaman yang diperlukan, dan keadaan mental dan emosi yang serasi.

Penelitian ini bertujuan untuk menganalisis kesiapan guru menerima anak usia dini berkebutuhan khusus di kelasnya, dan faktor-faktor psikologis yang mempengaruhi kesiapan tersebut. Diharapkan penelitian ini dapat memberikan pemahaman kepada guru mengenai kesiapan mengajar untuk anak berkebutuhan khusus, sehingga siswa merasa nyaman dan mudah dalam proses pembelajaran.

\section{Metode}

Penelitian ini merupakan penelitian kualitatif. Subyek penelitian adalah para guru TK di Kabupaten Buleleng, baik yang memiliki siswa berkebutuhan khusus di kelas atau sekolahnya maupun yang tidak. Data diperoleh dengan dua cara, pertama untuk data kesiapan psikologis guru dengan meminta responden mengisi kuesioner kesiapan psikologis guru, kedua, untuk memperdalam data tentang sikap guru, dilakukan diskusi kelompok terarah. Diskusi kelompok terarah bertujuan memperoleh pemahaman tentang sikap guru terhadap kehadiran anak berkebutuhan khusus di kelasnya, apakah positif atau negatif. Instrumen yang digunakan untuk mengumpulkan data adalah kuesioner.

Indikator pada kuesioner mengacu pada tiga hal, yaitu 1) pengetahuan tentang anak berkebutuhan khusus, 2) pengalaman, 3) keadaan mental emosi yang serasi. Pengetahuan 
berhubungan dengan pengetahuan guru terhadap pendidikan anak berkebutuhan khusus, sementara pengalaman berhubungan dengan tingkat penguasaan dan keterampilan. Guru yang mengajar anak berkebutuhan khusus dikatakan berpengalaman apabila memiliki tingkat penguasaan dan ketrampilan yang banyak atau tinggi terkait dengan anak berkebutuhan khusus. Keadaan mental emosi yang serasi berhubungan dengan sikap guru, yaitu di antaranya kritis, memiliki pertimbangan logis, obyektif dewasa dan memiliki emosi yang terkendali. Panduan diskusi kelompok terarah disusun dengan mempertimbangkan halhal yang mempengaruhi sikap guru, yaitu a) pemahaman subyek terhadap pendidikan inklusi, b) pemahaman tentang anak berkebutuhan khusus, c) kemampuan melakukan deteksi hambatan dan permasalahan anak usia dini, d) kemampuan memberikan stimulasi dan penanganan terhadap anak berkebutuhan khusus. Hasil kuesioner diolah menggunakan statistik deskriptif, untuk data diskusi kelompok terarah, teknik analisis yang digunakan adalah teknik analisis tematik.

\section{Hasil dan Pembahasan}

Langkah awal yang dilakukan yaitu menyebarkan seratus lembar kuesioner kepada guru TK dan pendidik PAUD di jenjang kelompok bermain dan TPA di Kabupaten Buleleng. Dari seratus kuesioner, sembilan puluh enam berhasil diisi oleh para pendidik PAUD dari 23 lembaga PAUD di Kabupaten Buleleng dan setelah melewati perhitungan statistik deskriptif diperoleh hasil bahwa 34,38\% menyatakan di sekolah/lembaga mereka ada anak berkebutuhan khusus, sementara 65,63\% menyatakan tidak ada anak berkebutuhan khusus di sekolah mereka. Untuk pemahaman responden terhadap karakteristik anak berkebutuhan khusus, diperoleh hasil bahwa $65,63 \%$ atau 63 orang dari responden menyatakan tidak memahami karakteristik anak berkebutuhan khusus, sementara $34,38 \%$ atau 33 orang menyatakan paham dengan karakteristik anak berkebutuhan khusus. Pada poin yang lain, sebanyak 49 orang menyatakan mampu melakukan asesmen sederhana pada anak berkebutuhan khusus atau setara dengan $51,04 \%$, sementara sisanya yaitu 47 orang atau $48,96 \%$ menyatakan belum mampu melakukan asesmen sederhana untuk mendeteksi kebutuhan khusus anak.

Mayoritas responden sejumlah 94 orang atau 98\% setuju bahwa setiap anak berhak mendapatkan pendidikan yang layak, bagaimanapun kondisinya. Sementara hanya 2,1\% yang tidak setuju. Dari hasil kuesioner juga diperoleh hasil bahwa hanya 22,92\% atau 22 responden yang menyatakan paham tentang program inklusi, sementara $77,1 \%$ belum memahami tentang program inklusi. Sebelas orang responden atau $11,46 \%$ dari keseluruhan responden menyatakan mampu mendesain program pembelajaran untuk anak berkebutuhan khusus, sementara delapan puluh lima orang lainnya atau $88,54 \%$ belum mampu mendesain program pembelajaran untuk anak berkebutuhan khusus. Delapan puluh tujuh atau sekitar $90,63 \%$ menyatakan membutuhkan pengetahuan dan keterampilan untuk melakukan asesmen dan mendesain pembelajaran untuk anak berkebutuhan khusus, hanya sembilan orang atau sekitar 9,4\% yang menyatakan tidak membutuhkannya. Dan terakhir, dari sembilan puluh enam responden, delapan puluh satu orang diantaranya atau sekitar $84,38 \%$ menyatakan bersedia menerima anak berkebutuhan khusus di kelasnya, sementara 15 orang sisanya menyatakan tidak bersedia (15,63\%).

Hasil diskusi kelompok terarah diolah dengan teknik koding berdasarkan topik atau tema yang muncul. Peserta diskusi kelompok terarah berjumlah tujuh orang yang terdiri dari kepala sekolah dan guru dari gugus VI Kabupaten Buleleng. Hasil dari diskusi menunjukkan bahwa seluruh peserta diskusi kelompok terarah tidak mengetahui secara mendetail tentang pendidikan inklusi. Hanya dua orang yang pernah mendengar dan hanya secara sekilas saja. Untuk pemahaman tentang anak berkebutuhan khusus, hampir seluruh peserta diskusi memiliki pemahaman bahwa anak berkebutuhan khusus adalah mereka yang memiliki cacat tubuh seperti tuna netra dan tuna daksa. Pemahaman lainnya adalah anak berkebutuhan khusus adalah anak nakal, susah belajar dan perilakunya 'bermasalah' atau 'susah dikendalikan'. Peserta juga menyatakan mereka memiliki kemampuan yang masih terbatas 
dalam melakukan deteksi hambatan dan permasalahan anak usia dini. Teknik-teknik asesmen yang terstruktur dan khusus untuk mendeteksi, terutama untuk anak berkebutuhan khusus, belum dikuasai dengan baik. Dari hasil diskusi juga diperoleh gambaran bahwa para guru sangat membutuhkan pengetahuan dan keterampilan dalam mendeteksi dan menyusun program pembelajaran untuk anak berkebutuhan khusus. Oleh karena masih sangat awam dengan cara melakukan asesmen, stimulasi dan penanganan yang diberikan pada anak berkebutuhan khusus juga amat terbatas. Namun demikian, meskipun peserta diskusi ratarata belum terlalu memahami tentang jenis-jenis kekhususan anak, namun dari pengalaman mengajar yang rata-rata cukup lama, mereka menyadari bahwa jumlah anak yang 'perlu diberi perlakuan khusus' secara kuantitas bertambah dibandingkan tahun-tahun sebelumnya. Berdasarkan hasil penelitian tersebut dapat disimpulkan bahwa pada dasarnya para guru TK memiliki sikap yang positif terhadap keberadaan anak berkebutuhan khusus di kelas. Para guru bersedia menerima anak berkebutuhan khusus untuk belajar bersama-sama dengan anak-anak lain di kelas reguler. Namun mereka merasa belum benar-benar siap karena tidak memiliki pengetahuan dan ketrampilan yang memadai, baik dari segi melakukan asesmen, memberikan stimulasi yang sesuai, hingga menyusun program pembelajaran sesuai kebutuhan anak.

Kesiapan guru dalam menangani anak berkebutuhan khusus di kelasnya akan terbentuk jika tercapai perpaduan antara tiga faktor, yaitu tingkat kematangan, pengalamanpengalaman yang diperlukan, dan keadaan mental dan emosi yang serasi (Hasibuan, Syamsuri, Santosa, \& Pamungkas, 2020; Lestari, 2015). Tingkat kematangan dipengaruhi oleh usia, kondisi fisik dan kematangan. Dari hasil penelitian ditemukan bahwa responden penelitian telah memiliki umur yang matang, kondisi fisik yang fit atau tidak menghalangi mereka dalam menjalankan tugas, dan rata-rata telah memiliki pengalaman mengajar yang cukup lama, yaitu lebih dari lima tahun. Namun, pengalaman mengajar anak berkebutuhan khusus adalah sesuatu yang baru dan dianggap asing oleh para guru, karena kemampuan, pengalaman, dan pelatihan yang mereka peroleh sebelumnya tidak banyak. Akibatnya, belum diperoleh kondisi mental dan emosi yang serasi terkait dengan kesiapan untuk menangani anak berkebutuhan di kelasnya. Hal ini disebabkan karena dalam menangani siswa berkebutuhan khusus, guru memerlukan pengetahuan mengenai anak berkebutuhan khusus, keterampilan mengasuh dan melayaninya (Habibi, 2017; Septianisa \& Caninsti, 2018).

Hasil pengolahan data kuesioner dan diskusi kelompok terarah menunjukkan para guru telah memiliki kesadaran bahwa setiap anak berhak untuk mendapatkan layanan pendidikan semaksimal mungkin, termasuk anak berkebutuhan khusus. Para guru mengembangkan sikap positif dan menyatakan bersedia menerima anak berkebutuhan khusus di kelasnya, namun ada rasa khawatir dari para guru karena merasa tidak memiliki pengetahuan, ketrampilan, kemampuan dan pengalaman yang memadai untuk melakukan asesmen dan menyusun program pembelajaran yang sesuai. Para guru menyatakan masih sangat awam terhadap teknik-teknik asesmen yang terstruktur dan khusus, dan untuk melakukan deteksi kebutuhan khusus anak. Oleh karena itu, mereka sangat membutuhkan pengetahuan dan ketrampilan dalam mendeteksi dan menyusun program pembelajaran untuk anak berkebutuhan khusus (Rudiyati, 2013; Winta \& Pribadi, 2020). Meskipun guruguru yang menjadi peserta diskusi kelompok terarah menyatakan bahwa hampir setiap tahun mereka menerima anak dengan kebutuhan khusus di kelasnya, namun mereka belum mengenal konsep pendidikan inklusi. Padahal program pendidikan inklusi adalah salah satu program pendidikan untuk mensukseskan gerakan pendidikan untuk semua dan dikukuhkan lewat Permendikbud No 70 Tahun 2009 (Amka, 2019; Praptiningrum, 2010).

Berdasarkan rangkuman yang disusun oleh Avramidis \& Norwich (2002) berbagai penelitian mengenai faktor yang mempengaruhi sikap guru terhadap anak berkebutuhan khusus dan pendidikan inklusi, maka dapat diuraikan bahwa terdapat faktor yang mempengaruhi kesiapan guru TK dalam penelitian ini. Guru belum siap karena belum memiliki pengetahuan yang memadai tentang konsep anak berkebutuhan khusus, siapa saja mereka dan hambatan apa yang dihadapi oleh siswanya, dan kebutuhan siswa terhadap 
pendidikan (Hamidaturrohmah \& Mulyani, 2020; Sulistianingsih \& Nurjannah, 2017). Sebagian besar guru hanya menyebutkan kebutuhan siswa mereka dengan istilah 'anak manja', 'anak bermasalah', dan 'anak nakal'. Untuk faktor gender, tidak ada perbedaan sikap guru berdasarkan gender. Guru laki-laki maupun perempuan sama-sama bersedia menerima anak berkebutuhan khusus di kelasnya. Dari faktor usia dan pengalaman belajar, tidak ada perbedaan sikap guru terhadap integrasi anak berkebutuhan khusus di kelasnya. Jika secara teori, guru yang lebih muda dengan pengalaman mengajar lebih sedikit lebih mendukung integrasi, maka para responden dalam penelitian ini semua menyatakan sikap positif dan mendukung keberadaan anak berkebutuhan khusus di kelas mereka, meskipun usia dan pengalaman mengajar mereka bervariasi. Faktor lain yang mempengaruhi sikap guru adalah pengetahuan yang dimiliki mengenai siswa berkebutuhan khusus yang dikembangkan melalui pelatihan yang didapat. Faktor ini dipertimbangkan menjadi faktor penting dalam mempengaruhi sikap guru terhadap pelaksanaan kebijakan inklusi. Guru perlu diberi pelatihan mengenai mengenai pendidikan untuk siswa berkebutuhan khusus, agar tidak sulit untuk mengikutsertakan siswa tersebut ke dalam kelas reguler (Khayati et al., 2020; Rudiyati, 2013). Guru-guru yang menjadi responden dalam pelatihan ini menyatakan mereka kurang mendapatkan pelatihan tentang asesmen dan penyusunan program pembelajaran yang sesuai dengan kebutuhan anak berkebutuhan khusus. Sehingga meskipun sikap mereka positif, namun ada kekhawatiran mereka tidak mampu menangani dengan benar dan sesuai dengan yang dibutuhkan. Meskipun demikian, mereka tidak pernah menolak kehadiran anak-anak yang dianggap memiliki kebutuhan khusus di kelas, meskipun pada akhirnya apa yang mereka lakukan di kelas sifatnya trial dan error.

Guru yang beranggapan bahwa kebutuhan khusus merupakan sesuatu yang melekat dengan siswa, memiliki cara mengajar yang kurang efektif dibandingkan dengan guru yang beranggapan bahwa lingkungan di sekitar siswa dapat menjadi pelengkap bagi masalah atau hambatan yang dimiliki siswa (Avramidis \& Norwich, 2002; Praptiningrum, 2010). Responden dalam penelitian ini memiliki keyakinan bahwa agar pemberian stimulasi dan proses pembelajaran dapat berlangsung maksimal, maka orang tua dan keluarga haruslah dilibatkan. Bukan hanya itu masyarakat sekitar juga perlu diberi pemahaman agar tidak melakukan diskriminasi dan mendukung upaya-upaya untuk memenuhi kebutuhan khusus anak. Faktor lain yang tak kalah pentingnya yang dapat mempengaruhi sikap positif guru adalah ketersediaan dukungan fasilitas di dalam kelas dan level sekolah (Mustafa, Murniati, \& Niswanto, 2018; Salmah \& Tamjidnoor, 2019). Para responden dalam penelitian ini menyatakan bahwa kepala sekolah dan guru lainnya bekerja bahu membahu dan saling mendukung terhadap keberadaan anak berkebutuhan khusus di sekolah mereka. Yang kerap menjadi hambatan adalah level pengetahuan dan ketrampilan mereka yang kurang lebih setara, sehingga dalam melakukan penanganan pun hanya mengandalkan pengetahuan yang mereka miliki dan berdasarkan trial error.

Implikasi penelitian ini yaitu kesiapan psikologis dari siswa sangat mempengaruhi keberhasilan belajar siswa berkebutuhan khusus. Selain itu guru harus menyadari mengenai kondisi dan kesiapan siswa berkebutuhan khusus dalam proses pembelajaran dan menggunakan metode atau model pembelajaran yang tepat agar menciptakan pembelajaran yang menyenangkan. Seluruh guru wajib memperhatikan kesiapan psikologi siswa dalam pembelajaran serta mengupayakan untuk mengatasi kendala psikologis dari siswa berkebutuhan khusus.

\section{Simpulan}

Berdasarkan uraian di atas, dapat disimpulkan bahwa pada dasarnya para guru TK memiliki sikap yang positif terhadap keberadaan anak berkebutuhan khusus di kelas atau sekolah mereka. Para guru bersedia menerima anak berkebutuhan khusus untuk belajar bersama-sama dengan anak-anak lain di kelas reguler. Namun mereka merasa belum benar-benar siap karena tidak memiliki pengetahuan dan ketrampilan yang memadai, baik dari segi melakukan asesmen, memberikan stimulasi yang sesuai, hingga menyusun 
program pembelajaran sesuai kebutuhan anak. Apa yang mereka lakukan hanya bersifat trial dan error.

\section{Daftar Pustaka}

Amka. (2019). Pendidikan Inklusif Bagi Siswa Berkebutuhan Khusus Di Kalimantan Selatan. Jurnal Pendidikan Dan Kebudayaan, 4(1). https://doi.org/https://doi.org/10.24832/jpnk.v4i1.1234

Astuti. (2017). Penerapan Pembelajaran Bilingual di TK Inklusi. Jurnal Pendidikan Anak, 3(1). https://doi.org/http://dx.doi.org/10.24235/awlady.v3i2.1540

Avramidis, E., \& Norwich, B. (2002). Teachers' Attitudes towards Integration/Inclusion: a Review of the Literature. Journal of Special Needs Education, 2(1). https://doi.org/https://doi.org/10.1080/08856250210129056

Cahyani, N. (2019). Psikodrama untuk Meningkatkan Empati Siswa di Sekolah Inklusif. Inklusi, 6(2), 259. https://doi.org/https://doi.org/10.14421/ijds.060204

Dewi, P. S. D., Pujianti, P. R., \& Magta, M. (2020). Pendidikan Inklusif pada Pembelajaran Taman Kanak-kanak (Studi Kasus pada TK Rare Bali Shool). Jurnal Pendidikan, 8(2). https://doi.org/https://doi.org/10.36232/pendidikan.v8i2.441

Diahwati, R., Hariyono, H., \& Hanurawan, F. (2016). Keterampilan Sosial Siswa Berkebutuhan Khusus Di Sekolah Dasar Inklusi. Jurnal Pendidikan : Teori, Penelitian Dan Pengembangan, 1(8), 1612-1620. https://doi.org/http://dx.doi.org/10.17977/jp.v1i8.6682

Elliot, S. (2008). The Effect of Teachers' Attitude Toward Inclusion on the Practice and Success Levels of Children with and without Disabilities in Physical Education. International Journal of Special Education, 23(3). https://doi.org/https://eric.ed.gov/?id=EJ833682

Habibi, N. (2017). The Use of Flashcards in Improving Vocabulary Mastery of Students with Disability. Inklusi Journal Of Disability Studies, 121. https://doi.org/https://doi.org/10.14421/ijds.040203

Hamidaturrohmah, \& Mulyani, T. (2020). Strategi Pembelajaran Jarak Jauh Siswa Berkebutuhan Khusus Di Sd Inklusi Era Pandemi Covid-19. Elementary: Islamic Teacher Journal, 10(1). https://doi.org/https://doi.org/10.21043/elementary.v8i2.7907

Hasibuan, H. Y., Syamsuri, S., Santosa, C. A. H. F., \& Pamungkas, A. S. (2020). Profil Pembelajaran Matematika pada Anak Berkebutuhan Khusus Ragam Slow Learner di Kelas Inklusif SMP Garuda Cendekia Jakarta. Journal Of Medives: Journal Of Mathematics Education Ikip Veteran Semarang., 4(1). https://doi.org/https://doi.org/10.31331/medivesveteran.v4i1.993.

Kartowagiran, B. (2015). Kinerja Guru Profesional (Guru Pasca Sertifikasi). Jurnal Cakrawala Pendidikan. https://doi.org/10.21831/cp.v3i3.4208

Khayati, N. A., Muna, F., Oktaviani, E. D., Hidayatullah, \& Fauzan, A. (2020). Peranan Guru Dalam Pendidikan Inklusif Untuk Pencapaian Program Tujuan Pembangunan Berkelanjutan (SDG's). Komunikasi Pendidikan, 4(1). https://doi.org/https://doi.org/10.32585/jkp.v4i1.440

Lattu, D. (2012). Peran Guru Bimbingan dan Konseling pada Sekolah Penyelenggara Pendidikan Inklusi. Jurnal Bimbingan Dan Konseling Terapan, 2(1). https://doi.org/http://dx.doi.org/10.30598/jbkt.v2i1.236

Leatherman, J. M., \& Niemeyer, J. A. (2005). Teachers' Attitudes Toward Inclusion: Factors Influencing Classroom Practice. Journal of Early Childhood Teacher Education, 26(1). 
Retrieved from https://www.tandfonline.com/doi/full/10.1080/10901020590918979

Lestari, F. (2015). Metode Guru Bk Dalam Mengatasi Problem Penyesuaian Diri Pada Anak Berkebutuhan Khusus. Inklusi Journal Of Disability Studies, 2(2). https://doi.org/https://doi.org/10.14421/ijds.2206

Mustafa, Murniati, \& Niswanto. (2018). Manajemen Sarana Pendidikan Pada Sekolah Anak Berkebutuhan Khusus Di SDLB YTC Kutablang Kabupaten Bireuen. Jurnal Administrasi Pendidikan, 6(1). $\quad$ Retrieved from http://jurnal.unsyiah.ac.id/JAP/article/view/11733

Nufus, Wulandary, \& Wahyuda. (2020). Demokrasi pendidikan: menolak UU pelarangan ganja RI dalam pembelajaran. Jurnal Civic Education, 4(1). https://doi.org/https://doi.org/10.36412/ce.v4i1.1869.

Oktiani, I. (2017). Kreativitas Guru dalam Meningkatkan Motivasi Belajar Peserta Didik. Jurnal Kependidikan. https://doi.org/10.24090/jk.v5i2.1939

Olson, J. M. (2003). Special Education and General Education Teacher Attitudes Toward Inclusion. Wisconsin-Stout: University of Wisconsin-Stout.

Praptiningrum. (2010). Fenomena Penyelenggaraan Pendidikan Inklusif bagi Anak Berkebutuhan Khusus. JPK (Jurnal Pendidikan Khusus), 7(2). https://doi.org/https://doi.org/10.21831/jpk.v7i2.774

Rudiyati, S. (2013). Peningkatan Kompetensi Guru Sekolah Inklusif Dalam Penanganan Anak Berkebutuhan Pendidikan Khusus Melalui Pembelajaran Kolaboratif. Cakrawala Pendidikan, 1(2). https://doi.org/https://doi.org/10.21831/cp.v0i2.1488

Salmah, S., \& Tamjidnoor. (2019). Aksesibilitas Pendidikan Bagi Kaum Disabilitas Pada Madrasah Ibtidaiyah Negeri (Min) Di Kota Banjarmasin. Al-Banjari: Jurnal IImiah IImuIImu Keislaman, 18(1). https://doi.org/https://doi.org/10.18592/al-banjari.v18i1.2995

Septianisa, S., \& Caninsti, R. (2018). Hubungan Self Efficacy Dengan Burnout Pada Guru Di Sekolah Dasar Inklusi. Jurnal Psikogenesis, 4(1). https://doi.org/https://doi.org/10.24854/jps.v4i1.523.

Setianingsih, E. S. (2018). Penerimaan dan Sikap Guru Terhadap Keberadaan Abk Di Sekolah. Jurnal Empati, 5(1). https://doi.org/https://doi.org/10.26877/empati.v5i1.2929.

Sinoho, T. (2011). Upaya Menuju Demokratisasi Pendidikan. Jurnal Ekonomi Dan Pendidikan, 8(1). https://doi.org/https://doi.org/10.21831/jep.v8i1.708

Suastariyani, N. K. N., \& Tirtayani, L. A. (2019). Survei Persepsi Orang Tua Mengenai Program Paud Inklusidi Kota Denpasar Tahun 2020. Jurnal Pendidikan Anak Usia Dini Undiksha, 8(2). https://doi.org/http://dx.doi.org/10.23887/paud.v8i2.25156

Sulistianingsih, \& Nurjannah. (2017). Upaya Sekolah Inklusif Smp Tumbuh Yogyakarta Dalam Menciptakan School Well-Being. Hisbah: Jurnal Bimbingan Konseling Dan Dakwah Islam, 13(2). https://doi.org/https://doi.org/10.14421/hisbah.2016.132-03

Surahman, E., \& Mukminan. (2017). Peran guru IPS sebagai pendidik dan pengajar dalam meningkatkan sikap sosial dan tanggung jawab sosial siswa SMP. Harmoni Sosial: Jurnal Pendidikan IPS, 4(1), 1-13. https://doi.org/https://doi.org/10.21831/hsjpi.v4i1.8660

Taylor, R. W., \& Ringlaben, R. P. (2012). Impacting Pre-service Teachers' Attitudes toward Inclusion. Higher Education Studies, 2(3). https://doi.org/https://doi.org/10.5539/hes.v2n3p16

Umi, R., Nopriansyah, U., \& Purnama, S. (2019). Korelasi kepemimpinan kepala taman kanak-kanak terhadap kinerja kompetensi pedagogik dan kompetensi profesional 
guru. Al-Athfaal: Jurnal Ilmiah Pendidikan Anak Usia Dini. https://doi.org/10.24042/ajipaud.v2i1.4552

Widyastono, H. (2007). Penyelenggaraan Pendidikan Inklusi Bagi Anak Berkelainan. Jurnal Pendidikan Dan Kebudayaan, 1365. https://doi.org/https://doi.org/10.24832/jpnk.v13i65.340

Winta, M. V. I., \& Pribadi, A. S. (2020). Pelatihan Pemahaman tentang Coping Stress yang Tepat pada Guru Sekolah Inklusi. Jurnal E-DIMAS, 11(4). https://doi.org/https://doi.org/10.26877/e-dimas.v11i4.4477

Yusuf, M. (2012). Kinerja Kepala Sekolah dan Guru dalam Mengimplementasikan Pendidikan Inklusif. Jurnal Pendidikan Dan Kebudayaan, 18(4). https://doi.org/https://doi.org/10.24832/jpnk.v18i4.96 